\title{
Pressure to publish stifles young talent
}

Sir - Almost three years have passed since the last government Research Assessment Exercise (RAE) conducted on UK universities. The next exercise will take place in 2001 and many universities are planning for the future with some anxiety. The consequences for departments that fail to retain ratings of 4 or 5 on the 5-point scale are dire. A lower score would mean loss of funding that might lead to redundancies. Meanwhile departments with ratings of 2 or 3 are already fighting for survival. All universities are trying to reach set RAE targets. Some plans are realistic, others may not be. Either way the pressure is rising.

One obvious strategy is to remove staff less active in research, encourage early retirements and replace with new, probably younger, academic staff. However, recruitment has to be carried out with increasing haste. The job requirements for this new generation of academic staff seem overwhelming and many post-doctoral researchers may feel inadequately prepared.

The RAE committees in the laboratory science areas require four excellent peerreviewed publications. These will be the basic requirement for posts in the universities. Is that really beyond the capability of most young researchers?

To test this hypothesis, I retrieved from the BIDS database the publication record of ten scientists in my own field of molecular microbiology, who have been based throughout their entire careers in the UK.

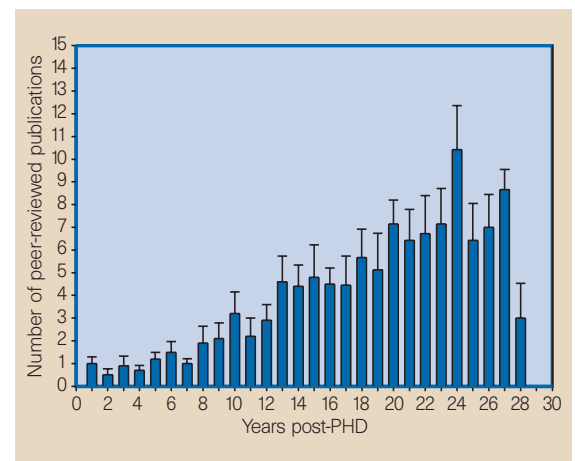

Building to a peak: would these high achievers have made it through the present system?

They are now in very senior positions in universities or research institutes; their careers span a total of 262 years. They have all achieved worldwide status and respect. The question I posed was: "How would they have matched the criteria for RAE in the early stages of their careers?"

The graph above shows mean publication rate (with standard error indicated by bars) per year after completing their $\mathrm{PhDs}$. The data were collected from the BIDS database as publications back to 1981 . I had to rely upon citations for my information before this time. Despite this handicap, it was clear that all the scientists produced a number of cited publications, often citing their own research in publications after 1981 .

The pattern of publication output over their careers is revealing. Generally they produced few papers over the first ten years, although the quality of the work was clearly outstanding. During that time, each one went for an average of 3.8 years without apparently publishing (or producing a cited paper) at all. In one case there was a five-year gap! The conclusion I reached from this simple exercise is that application of the current RAE exercise might have precluded all of them from appointments to academic posts.

These scientists went on to do great things. They have initiated novel, sometimes risky research and built up new avenues of endeavour along with highly respected research groups. Indeed, their later publications reflect the increasing number of collaborations that they have generated.

The careful nurturing of young talent has had its rewards for UK science. The atmosphere that surrounds the RAE may be stifling the talented, either by reducing the urge to take imaginative risks in new areas or by simply driving them out of science. Those who take up the challenge may find the pressure to perform very hard to bear. The management of research in universities may become tyrannies that allow little time for thinking, teaching, home life or young families. One thing is certain: without committed and imaginative young scientists who enjoy the challenge of discovery, the future of UK science will not be fruitful. Michael J. Larkin

The Questor Centre, The Queen's University Belfast, Stranmillis Road, Belfast BT9 5AG, UK

\section{Language bias discredits the peer-review system}

Sir - The system of refereeing original articles in science is based on what is called "peer judgement". The term "peer" means "equal in rank and abilities", but this is far from reality. Journal referees are usually experts in their fields, meaning that most of us are refereed by our superiors. Their criticism is usually very constructive.

There is, however, a point on which the peer-review system is discriminatory: language. Almost all the referees' comments mention style. They usually say that the manuscript must be revised by a native English speaker. For many researchers, English is a second language learned in adulthood. This prevents us having the same command as an English speaker.

I write my articles in English, then I pay a native English speaker (British or American, usually with a university science degree) to correct the spelling, grammar and style. On one occasion, I asked an English friend to correct one of my papers. He is a professor at Oxford University, a well known expert in his field with more than 250 papers published, and is editor-in-chief of a reputed journal. He did an intense revision of the manuscript. In spite of this, one of the referees said the manuscript should be revised by a native English speaker, without any specific criticism about the style.

What can I say? I guess for this referee, any style different from his own is inadequate. That kind of comment makes editors send a paper back to the author for revision. That is a waste of money, time and morale, especially when there is nothing to correct. I recommend referees to be more aware of this fact when judging manuscripts from nonEnglish-speaking countries.

I have thought of a possible solution: the creation of what I have tentatively called an Institute for Correct English Style (ICES). Through this, qualified people would ensure that the paper is written correctly and the institute would issue a certificate of competence in English. A paper corrected by an
ICES member would not need referees' judgements on style. Reviewers would then focus on their real expertise: science. The peer-review system would again be equal.

Under the present system, if Romeo and Juliet had been written by González instead of Shakespeare, this great work would have been rejected.

\section{Antonio J. Herrera}

Departamento de Bioquimica, Bromatologia y Toxicologia, Facultad de Farmacia,

Universidad de Sevilla, Spain

\section{German job security leads to stagnation ...}

Sir - Your editorial and News report touch on fundamental problems that have beset German universities for a long time (Nature 396, 393 \& 396; 1998). The system is rigid and bureaucratic with little incentive for efforts beyond minimal requirements.

Many professors strive to achieve high standards against a gradient of adverse 
conditions dictated by federal and state university laws, compounded by legal systems that rule on salaries for technical and academic staff. The result is a stable system, but one that favours the mediocre. Salaries depend solely on age, family status, and years in the job.

After five years at the university, everyone attains the right to permanent, tenured employment almost regardless of quality. As such positions are usually already filled and are no longer created, a well trained technician or academic staff member has to leave even if funds for their salary are available from research grants and they do not necessarily seek permanent employment.

Compared to the United States, tenure is reached early and in high numbers. This creates complacency. Furthermore, no university in Germany (except a few private institutions) can select their students. They have no influence on selection criteria or numbers admitted, and no student pays a single Pfennig for tuition. No wonder that calls for payment by results are opposed.

But at least some faculties have begun to reallocate their scarce resources on the basis of objective criteria that allow the assessment of research results.

\section{Eberhard Passarge}

Institut für Humangenetik, Universitätsklinikum Essen, D-45122 Essen, Germany

\section{... and reduces students' chances of publishing}

Sir - It is essential to introduce pay by results and to abolish civil servant status for university teachers in Germany. Civil servant status - commonly known as a synonym of inefficiency - prevents the firing of academics who can't compete in the 'publish or perish' world of science. Academics should face competition, in the same way as every other part of the labour market does.

During my studies in Germany I observed that the lack of an efficient system for the evaluation of university teachers leads to a growing class of academics who know that their performance does not affect their income. (I do not want to attack those who accept the rules of competition and know that their reputation depends on the quality of their publications.)

Lecturers usually neglect their teaching duties, and deliver the same lectures unchanged for years. From my experience I know that students with less renowned supervisors have to work harder to have research published, and often do not get a job in industry because in a tough job market the reputation of the supervisor is essential. Their work is not assessed fairly and they won't get the chance to prove their abilities. Because such incompetent supervisors waste time on inefficient administration, they cannot provide the necessary support to students. They lack the skills to submit applications for funds, so their students have to finish their work on state benefits. But such supervisors can't lose their posts.

I do not support the call to abandon Habilitation, the postdoctoral qualification required to become a member of the teaching staff. Habilitation is necessary for a fair judgement of the individual's skills as a leader and manager.

For the sake of good research and education in Germany, the introduction of competition at universities is overdue. Payment by results only threatens the incompetent. Students are evaluated every day - so why not their teachers?

\section{Andreas Herde}

Dyson Perrins Laboratory, Oxford OX1 3QY, UK

\section{Frémiet's phantasms}

Sir - As a one-time 'fledgling palaeontologist' inspired by Frémiet's sculptures in the Paris Jardin des Plantes, I read with interest Martin Kemp's piece on their relevance to the public understanding of palaeontology and evolution (Nature, 396, 727; 1998).

However, his interpretation prompts some comments.

Besides the bronze relief Man Triumphant over Two Bears, shown by Kemp, there is another sculpture by Frémiet in the Jardin des Plantes depicting the struggle between man and bear - with apparently a completely different outcome. Le dénicheur d'oursons ('Bear Cub

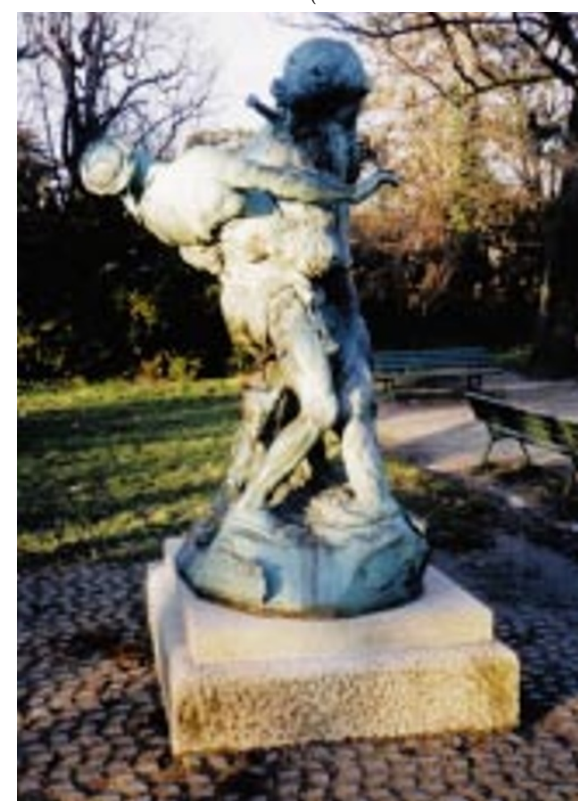

Darwinism or symbolism? Emmanuel Frémiet's Bear Cub Snatcher, Jardin des Plantes, Paris.
Snatcher') is a large bronze statue standing near a children's playground not far from the Galerie d'Anatomie Comparée et de Paléontologie. It shows a prehistoric hunter, a strangled bear cub tied to his waist, in the deadly embrace of an adult bear (presumably the mother). There is a knife stuck in the bear's throat, but the animal is clearly in the process of breaking the hunter's back. This statue is thus a 'mirror image' of man triumphant. So, even in the popular scientific mythology of the late nineteenth century illustrated by Frémiet's work, the triumph of man over beast was far from assured (as also in Frémiet's Orang-utan strangling a native of Borneo, also shown by Kemp).

But the prominence of Frémiet's depiction of the struggle between primitive man and beasts in the Galerie d'Anatomie Comparée et de Paléontologie is actually something of a paradox. Kemp's labelling of Albert Gaudry, who conceived the Galerie, as "the leading French advocate of Darwin's theories" is misleading.

Gaudry was an evolutionist, and wrote that he had read Darwin's Origin of Species "with passionate admiration" and had "savoured it slowly, as one drinks a delicious liqueur". Nonetheless he had no taste for natural selection as envisioned by Darwin, and admitted that he was "far from Darwin's philosophical ideas in some respects". (Gaudry's quotations here are translated from ref. 1).

Because of his strong religious belief in a harmonious Creation, in which chance and struggle had no place, Gaudry developed an idyllic view of evolution ${ }^{2}$, in which carnivores fed on herbivores to put an end to their sufferings when they grew old, and living beings developed according to a benevolent divine plan. He was convinced that "there was no competition for life, everything was harmonious". This was a far cry from mainstream Darwinism, especially its nineteenth-century incarnation.

Seen in that light, Frémiet's work stands as a symbol for the triumph of the human spirit (seen by Gaudry as the "marvel of Creation") over brute strength rather than a depiction of a Darwinian struggle for life.

In any case, whatever their exact cultural significance, these late nineteenthcentury sculptures are more artistically interesting than the derelict and scientifically inaccurate fibreglass stegosaur, a late twentieth-century addition, that now 'adorns' the grounds of the Galerie d'Anatomie Comparée et de Paléontologie. Eric Buffetaut

Centre National de la Recherche Scientifique 16 cour du Liégat, 75013 Paris, France

1. Gaudry, A. Les ancêtres de nos animaux dans les temps géologiques (Baillière, Paris, 1888).

2. Buffetaut, E. A Short History of Vertebrate Palaeontology (Croom Helm, London, 1987). 